\title{
Designing Formalwear for Female Teenagers with Dress Codes: A Co-creative Approach
}

\author{
Kendra Lapolla, Kent State University, Kent, OH, USA
}

Keywords: Co-creation, formalwear, dress codes

For teenage females there is a fine line between how one perceives dress as pretty or provocative. Specifically, contemporary fashion styles for school sponsored formal events like prom and homecoming have generated differing perceptions about what is acceptable for girls' dress which in turn has triggered a recent rise in dress codes defined by administrators for these events. These dress codes have been focusing particular attention to girls' attire (Pomerantz, 2007). Past research has explored the effect of dress codes on teenage females in everyday classroom settings (Raby 2010; Pomerantz 2007), and with a few exceptions scholarly research has often overlooked the high school prom (Zlatunich, 2009). This research attempts to fill a gap by focusing on the challenges of dress codes for formal events such as prom and homecoming where the financial investment is higher and there is more pressure to achieve the perfect look. By using co-creative research methods this study explores what kinds of dress designs these girls ideally desire and how girls feel about the dress code restrictions.

Co-creative research methods engage people in activities that generate tangible artifacts as a means to encourage discussion, reflection and valuable insights on a topic (Sleeswijk Visser $\&$ Visser, 2006). Through the process of making artifacts such as drawings, collages and models, participants can express deeper levels of knowledge about their experiences (Sleeswijk Visser, et al. 2005) The benefits of co-creative research methods are important because people are free to communicate and collaborate within organizations and across disciplines (Steen, Manschot, \& De Koning, 2011). Using co-creative research methods in this study is also valuable because consumption experiences have now shifted towards active experiences that engage consumer creativity (Moreau, 2011), which is evident in the "I designed it myself" effect from proud consumers creatively contributing to a product (Frank, Schreier, \& Kaiser, 2010).

Data for this study was collected using co-creative research methods with twelve female secondary school students in the Northeast United States. The students ranged from freshman to senior and were enrolled in two different secondary schools that each held dress codes for formal events. The co-creative workshops were held at participants' schools to encourage a comfortable, familiar environment. The participants were first asked to evaluate eight dress code acceptable design ideas created by the researcher. These designs were illustrated in black and white without indication of hair color, style, skin tone or facial features to keep participants focused on the dress. The participants discussed which dresses they would wear and how they might alter the designs to better fit their style. Then, participants were given a fashion croqui to create their own ideal dress. For this exercise, they were given illustrated flats of silhouette ideas and photographs of dresses to cut apart and collage on the croqui to create their ideal dress. After they created their ideal dress, they described it to the group and had an open discussion about the challenges of finding a special occasion dress when restricted to a school dress code. 
Findings from the co-creative workshops revealed that the strict dress codes often conflicted with suggestive retail offering of dresses. While some students felt the dress code was too strict, many felt retailers were not offering them enough modest options. These students indicated retailers could also offer more variety in sizing and style to benefit their unique needs. What worked for someone tall, did not for those that were short or plus size. It was also clear that this demographic feels very confident and comfortable being creative with things they care about. While designing their ideal dresses, it was apparent these participants would enjoy being involved with the personalization of their special occasion dresses. These findings have several implications for school administrators and current retailers offering special occasion dresses. School administrators would benefit from understanding of how different teenage female body shapes and sizes affect the dress fit. A dress acceptable for one girl and may not be for someone else. Retailers may benefit from finding ways to offer more variety in sizing and styles. These retailers may also consider consulting female teenagers for opinions on dress designs early on in the design process. Students in this study also identified a new design possibility for retailers to offer mix and match separates for formal wear. Students could then combine unique options and have other ways to wear the pieces after the formal event was over.

Franki, N., Schreier, M., \& Kaiser, U. (2010). The "I designed it myself" effect in mass customization. Management Science, 56(1), 125-140.

Moreau, P. (2011). Inviting the amateurs into the studio: Understanding how consumer engagement in product design creates value. The Journal of Product Innovation Management, 28(3), 409-410.

Pomerantz, S. (2007). Cleavage in a Tank Top: Bodily Prohibition and the Discourses of School Dress Codes. Alberta Journal of Education Research, 53(4), 373-386.

Raby, R. (2010). “Tank tops are ok but I don't want to see her thong” Girls' engagements with secondary school dress codes. Youth \& Society, 41(3), 333-356.

Sleesqijk Visser, F.S. \& Visser, V. (2006). Re-using users: co-create and co-evaluate. Personal and Ubiquitous Computing, 10(2-3), 148-152.

Sleesqijk Visser, F.S., Stappers, P.J., Van der Lugt, R., \& Sanders, E. B.-N. (2005). Contextmapping: Experiences from practice. CoDesign: International journal of CoCreation in Design and the Arts, 1(2), 119-149.

Steen, M., Manschot, M., \& De Koning, N. (2011). Benefits of co-design in service design project. International Journal of Design, 5(2), 53-60.

Zlatunich, N. (2009). Prom Dreams and Prom Reality: Girls Negotiating "Perfection" at the High School Prom. Sociological Inquiry, 79(3), 351-375. 